\title{
Photodegradation of Organosilane Self-assembled Monolayers Irradiated with an Excimer Lamp
}

\author{
Hiroyuki Sugimura, Takashi Shimizu and Osamu Takai \\ Department of Materials Processing Engineering, Graduate School of \\ Engineering, Nagoya University, Nagoya 464-8603, Japan
}

\begin{abstract}
Photodegradation of organosilane self-assembled monolayers (SAMs), under the presence of atmospheric oxygen molecules, has been studied using an excimer lamp radiating vacuum ultra-violet (VUV) light of $172 \mathrm{~nm}$ in wavelength. The SAMs were prepared on $\mathrm{Si}$ substrates covered with native oxide from a precursor molecule of octadecyltrimethoxysilane $\left[\mathrm{CH}_{3}\left(\mathrm{CH}_{2}\right)_{17} \mathrm{Si}\left(\mathrm{OCH}_{3}\right)_{3}\right.$, ODS]. Each of these SAMs was photoirradiated under a controlled pressure from 10 to $10^{5} \mathrm{~Pa}$. As confirmed by water contact angle measurements, infrared reflection-absorption spectroscopy and X-ray photoelectron spectroscopy, the SAMs were decomposed and removed due to the VUV-irradiation. This photodegradation mechanism is ascribed to dissociative excitation of $\mathrm{C}-\mathrm{C}$ and $\mathrm{C}-\mathrm{H}$ bondings in the ODS molecules and to subsequently proceeded oxidation with atomic oxygen radicals generated simultaneously by the VUV-irradiation of $\mathrm{O}_{2}$ molecules. This VUV-degradation of organosilane SAM was, furthermore, applied to to photolithography in which the SAM served as photoresist. A micropattern of $2 \mu \mathrm{m}$ in width was successfully transferred on the Si substrate by a simple photomask-contacting method.

Keywords: organosilane self-assembled monolayer, photodegradation, vacuum ultra-violet light, excimer lamp
\end{abstract}

\section{Introduction}

Self-assembled monolayers (SAMs) formed from organosilane molecules on oxide surfaces terminated with hydroxyl $(\mathrm{OH})$ groups through silane coupling chemistry between the molecules and the surface $\mathrm{OH}$ sites are widely applied to control physical and chemical properties of the surfaces [1], and have attracted much attention as resist materials for photolithography and other high-resolution lithographies [2]. In addition, microstructured SAMs were applied to microtemplates for spatial arrangement of biomolecules and cells [3], and for area-selective depositions of metals, minerals, polymers, etc. [4]. Micropatterning of organosilane SAMs is a key technology to utilizing such advanced applications.

Among various patterning technologies, photolithography is most practical, since it can transfer an entire pattern on a photomask to a resist film at a single time. However most of organosilane
SAMs have no sensitivity to ultra-violet light used in the conventional photolithography. Hence, organosilane SAMs has been photopatterned so far based on particular photochemistries of aromatic [5], mercapto [6] or chloride [7] organosilane SAMs using deep ultra-violet light near $200 \mathrm{~nm}$ or longer in wavelength. However, these photochemistries are not applicable to patterning of alkylsilane SAMs, in spite that such SAMs are most frequently used for surface modification.

A promising alternative way is the use of vacuum ultra-violet (VUV) light whose wavelength is much shorter than $200 \mathrm{~nm}$. As we have reported previously [8], alkylsilane SAMs could be decomposed and micropatterned under VUVirradiation at $172 \mathrm{~nm}$ in wavelength through a photomask. In order to optimize this VUVlithography, it is crucial to elucidate photochemistries proceeding when the SAMs are irradiated with VUV-light. 
In this paper, we report on VUV-photodegradation of an alkylsilane SAM in the presence atmospheric oxygen. The SAM was irradiated with an excimer lamp under controlled pressures ranging from 10 to $10^{5} \mathrm{~Pa}$. A possible photodegradation mechanism of the SAMs behind the VUV-lithography is discussed.

\section{Experimental}

\subsection{Sample preparation}

Sample substrates cut from Si wafers were photochemically cleaned by a UV/ozone cleaning method so as to become completely hydrophilic with their water-contact angles changing from more than $40^{\circ}$ before cleaning to almost $0^{\circ}$ afterwards. Due to this cleaning, a thin oxide layer, whose surface was most likely terminated with $\mathrm{OH}$ groups, formed on the Si substrates. Onto the photochemically cleaned samples covered with $\mathrm{OH}$ groups, SAMs were formed through a chemical vapor deposition (CVD) method. The cleaned samples were placed together with a glass cup filled with $0.2 \mathrm{~cm}^{3}$ organosilane liquid, octadecyltrimethoxysilane [ODS: Tokyo Kasei Organic Chemicals, $\left.\mathrm{CH}_{3}\left(\mathrm{CH}_{2}\right)_{17} \mathrm{Si}\left(\mathrm{OCH}_{3}\right)_{3}\right]$, into a $65 \mathrm{~cm}^{3}$ Teflon $^{\mathrm{TM}}$ container. The container was sealed with a cap and placed for 3 hours in an oven maintained at $150{ }^{\circ} \mathrm{C}$. The ODS liquid in the vessel vaporized and reacted with the $\mathrm{OH}$ groups on the sample surfaces. The molecules were fixed onto the surfaces and connected to adjacent ODS molecules through siloxane ( $\mathrm{Si}-\mathrm{O}-\mathrm{Si}$ ) bondings. As schematically illustrated in Fig.1, such an organosilane SAM consists of a two dimensional $\mathrm{Si}-\mathrm{O}-\mathrm{Si}$ network and an organic layer with a monomolecular thickness. The thicknesses of the

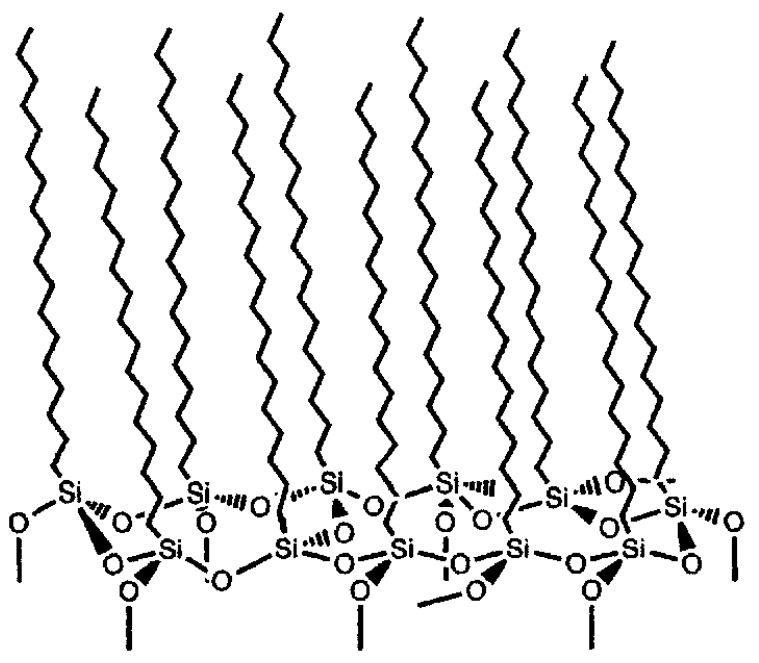

Fig. 1 Octadecylsilyl self-assembled monolayer (ODS-SAM)
ODS-SAM estimated by ellipsometry was $1.9 \pm$ $0.1 \mathrm{~nm}$. Details of this CVD method have been described elsewhere [9].

\subsection{Photoirradiation experiments}

Photodegradation of the ODS-SAM was studied by using an apparatus as depicted in Fig. 2. An ODS-SAM sample was placed in a vacuum chamber which was evacuated by a rotary pump. Pressure in the chamber was controlled by introducing air through a variable leak valve. The sample was then irradiated with VUV-light (an excimer lamp, Ushio Electric, UER20-172V, $\lambda=$ $172 \mathrm{~nm}$ and $10 \mathrm{~mW} / \mathrm{cm}^{2}$ at outside of the window) through a quartz glass disk of $10 \mathrm{~mm}$ thickness. Transparency of this quartz glass was ca. $70 \%$ at $\lambda$ $=172 \mathrm{~nm}$. Three configurations were employed in this study. The first was the configuration in which the quartz disk was placed $10 \mathrm{~mm}$ above the sample surface. In the second configuration, the quartz disk was placed directly on the sample surface as shown in Fig. 2B. In the final configuration as shown in Fig. $2 \mathrm{C}$, a 2 -mm thick quartz plate (Transparency of $93 \%$ at $\lambda=172 \mathrm{~nm}$ ) with a spacer $\mathrm{Cr}$ film of $0.1 \mu \mathrm{m}$ in thickness was inserted between the quartz disk and the sample. These configurations are referred to as $g=10,0$ and $0.0001 \mathrm{~mm}$, respectively. After the VUVirradiation for an appropriate period, the sample was taken out in order to measure its water contact angle using a contact anglemeter (CA-D, Kyowa Interface Science) based on the sessile drop method. Some of the photoirradiated ODS-SAM samples were analyzed by infrared reflection absorption spectroscopy at an incidence angle of $80^{\circ}$ (Biorad Laboratories, FTS-175C and Spectramono) and $X$-ray photoelectron spectroscopy (XPS, Shimazu-Kratos, AXIS).

\subsection{VUV-photopatterning}

An ODS-SAM sample was photolithographically micropatterned as follows. The SAM surface was irradiated through a photomask composed of a $2 \mathrm{~mm}$-thick quartz plate and a $0.1 \mu \mathrm{m}$-thick $\mathrm{Cr}$ film micropattern. The photomask was placed on the SAM as similarly to Fig. 2C. The photo-patterned SAM surface was then treated for $10 \mathrm{~min}$ in an aqueous solution of $0.1 \mathrm{wt} . \% \mathrm{HF}$ in order to remove $\mathrm{SiO}_{2}$ in the photoirradiated region. The ODS-SAM endured for more than $10 \mathrm{~min}$, while an etch rate of $\mathrm{SiO}_{2}$ in $0.1 \mathrm{wt} . \% \mathrm{HF}$ was ca. 0.5 $\mathrm{nm} / \mathrm{min}$. The SAM had sufficient durabilities as an etch mask for native $\mathrm{SiO}_{2}$ of ca. $2 \mathrm{~nm}$ thickness. 
$\mathbf{A}$

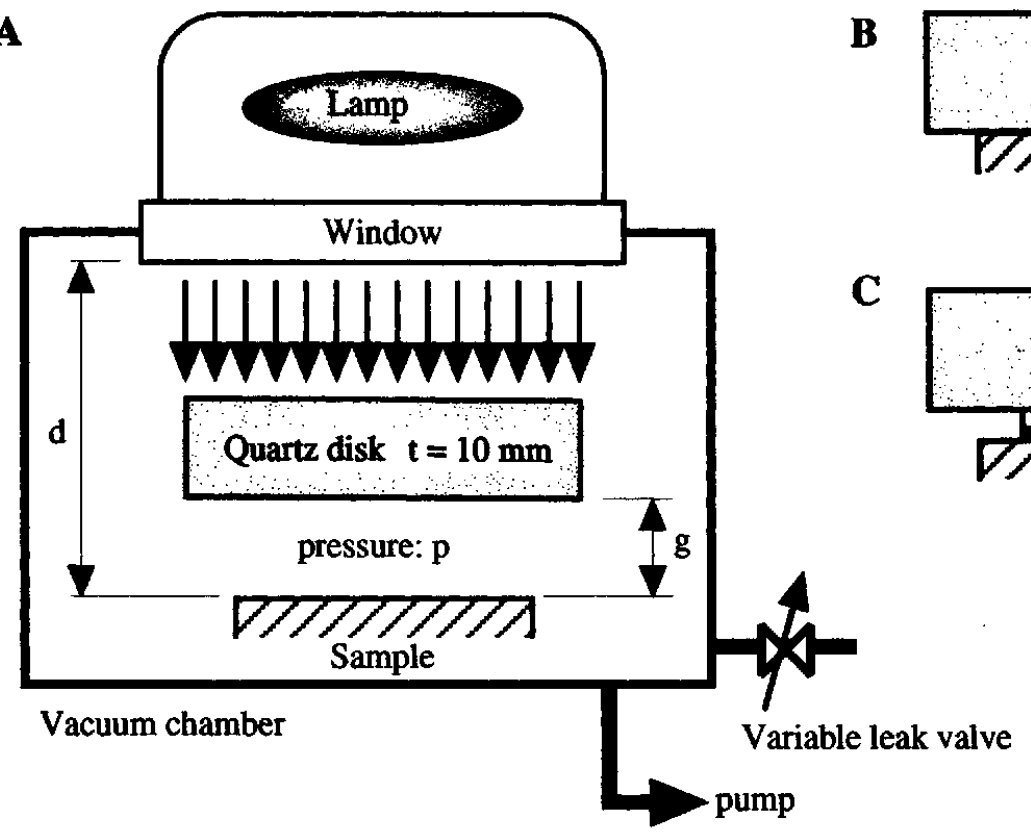

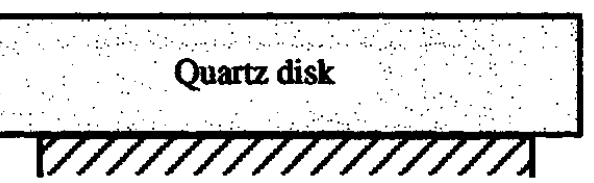

Sample
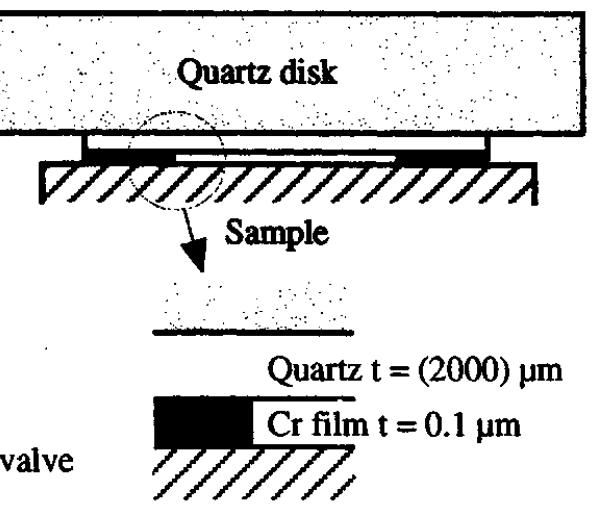

Fig. 2 Schematic diagram of the VUV-irradiation system (A). Experimental setups for attaining $g=0$ (B) and $g=0.2 \mu \mathrm{m}(C)$.

Next, the sample was further etched for $5 \mathrm{~min}$ in a solution of $\mathrm{NH}_{4} \mathrm{~F} / \mathrm{H}_{2} \mathrm{O}_{2} / \mathrm{H}_{2} \mathrm{O}$ (10:3:100 weight ratios). The sample was finally rinsed in pure water and then dried with a $\mathrm{N}_{2}$ blow.

\section{Results and discussion}

Changes in water contact angles of the ODSSAM samples photoirradiated with the configuration of $\mathbf{g}=0$ were plotted in Fig. 3. As photoirradiation was prolonged, water contact angles of the sample surfaces decreases and finally become almost $0^{\circ}$. We confirmed on the basis of XPS results that carbon concentrations on the photoirradiated ODS-SAM surfaces decreased with the photoirradiation time and approached those of a cleaned Si substrate prior to SAM-coating, i.e., a background level.

Figure 4 shows IR spectra of the ODS-SAM before and after photodegradation at a pressure of $10 \mathrm{~Pa}$. Spectrum A shows the spectrum of the undegraded ODS-SAM in which absorption peaks corresponding to $\mathrm{C}-\mathrm{H}$ bondings can be seen. Intensities of these peaks decrease due to photodegradation. The peaks become almost undetectable at an irradiation time of $30 \mathrm{~min}$ as shown in spectrum $\mathrm{C}$, although at this irradiation time, the ODS-SAM surface shows a water contact angle of ca. $60^{\circ}$ and have not completely decomposed yet.

As shown in Fig. 3, the photodegradation rate of the ODS-SAM is markedly accelerated when a pressure increases from 10 to $10^{2} \mathrm{~Pa}$. Oxygen may play some roles in the photodegradation. The degradation rate slightly increases with a pressure increase from $10^{2}$ to $10^{4} \mathrm{~Pa}$. These results are the evidence that oxygen diffused through a very thin gap between the quartz disk and the sample surface. On the contrary, the rate decreases when the pressure further increases to $10^{5} \mathrm{~Pa}$. At this pressure, i.e., ca. $1 \mathrm{~atm}$, the intensity of VUV-light reached to the SAM surface becomes considerably weaker, since VUV-light is greatly absorbed by oxygen in atmosphere (Transparency of 10-mm air layer at $10^{5} \mathrm{~Pa}$ is $\mathrm{ca} .10 \%$ ).

Since oxygen has crucial roles in the photodegradation of the ODS-SAM, the gap length between the quartz disk and the sample, i.e., $g$ value, is of particular importance. Thus, the gaplength effect on the photodegradation was studied as shown in Figs. 5 and 6.

Figure 5 shows the results obtained under the configuration of $g=10 \mathrm{~mm}$. In this case, the larger window-sample distance, $d$, of $27 \mathrm{~mm}$ was employed in order to attain enough space. The degradation rate becomes faster with an increase in pressure form 10 to $10^{3} \mathrm{~Pa}$, while the rate decreases when a pressure further increases to $10^{5}$ $\mathrm{Pa}$. However, in the all pressure range of $10 \sim 10^{5}$ $\mathrm{Pa}$, the photodegradation rates at $\mathrm{g}=10$ are much faster than the rates at $\mathrm{g}=0$ even though 
attenuation of light intensity at the SAM surfaces due to adsorption with atmospheric oxygen is greater at $d=27 \mathrm{~mm}$ than that at $d=17 \mathrm{~mm}$.

The changes in contact angle due to the VUVirradiation acquired using the configuration of $\mathrm{g}=$ 0.0001 are indicated in Fig. 6. This configuration

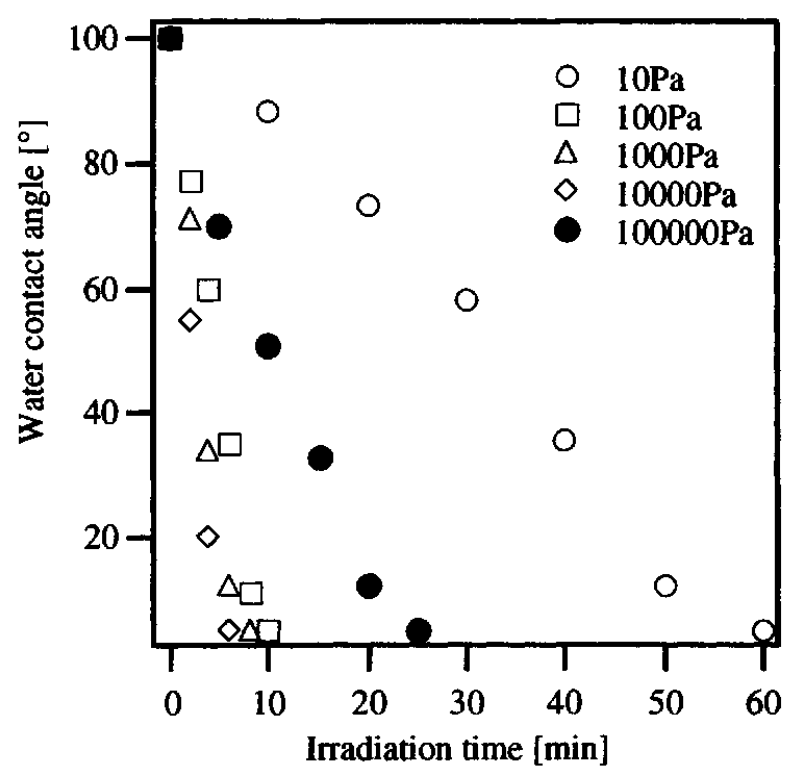

Fig. 3 Changes in water contact angle due to VUV-irradiation at $\mathrm{g}=0 \mathrm{~mm}$. and $\mathrm{d}=17 \mathrm{~mm}$.

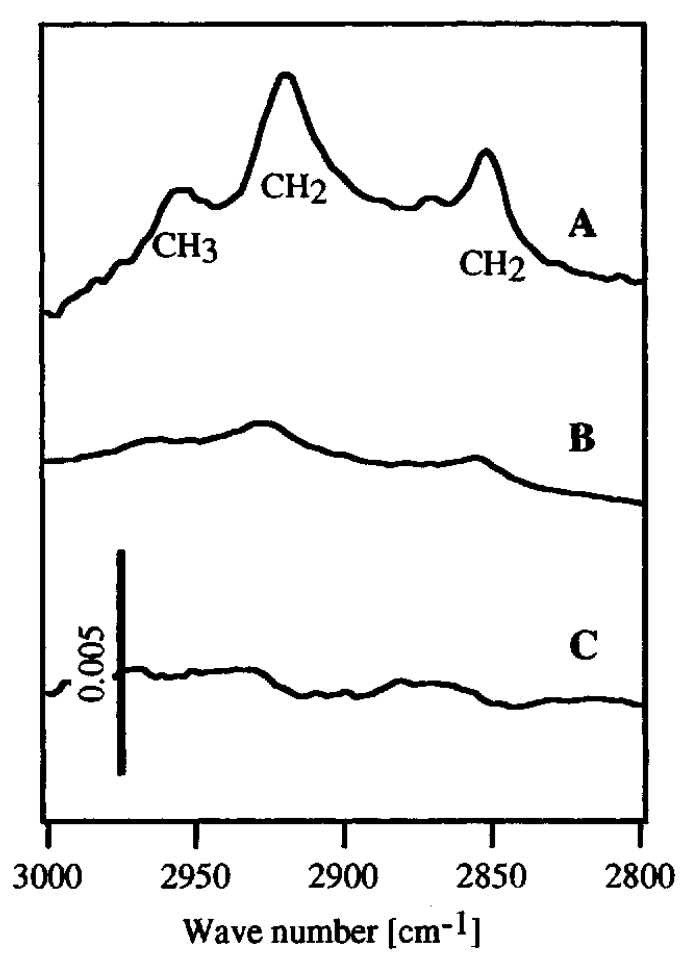

Fig. 4 IR-RAS of ODS-SAM photodegraded under the configration of $\mathrm{g}=0 \mathrm{~mm}$ at $10 \mathrm{~Pa}$. A) Undegraded ODS-SAM, B) ODS-SAM irradiated for $20 \mathrm{~min}$, and C) iradiated for $30 \mathrm{~min}$. corresponds to the situation when a photomask has been placed on a sample surface. In this case, a $\mathrm{Cr}$ pattern, which shields light, on the quartz glass plate work as a very thin spacer between the glass plate and the sample surface. The rate at $10 \mathrm{~Pa}$ is twice faster than the rate at the same pressure and $g$ $=0$. The rates at the other pressures are slightly faster than those at $g=0$. Considering that the VUV-light reaching the SAM surface has a loss of $7 \%$ due to the additional quartz plate of $2 \mathrm{~mm}$ thick, we can conclude that the small gap of 0.1 $\mu \mathrm{m}$ served as an effective pass for supplying oxygen and, consequently, enhanced photodegra-

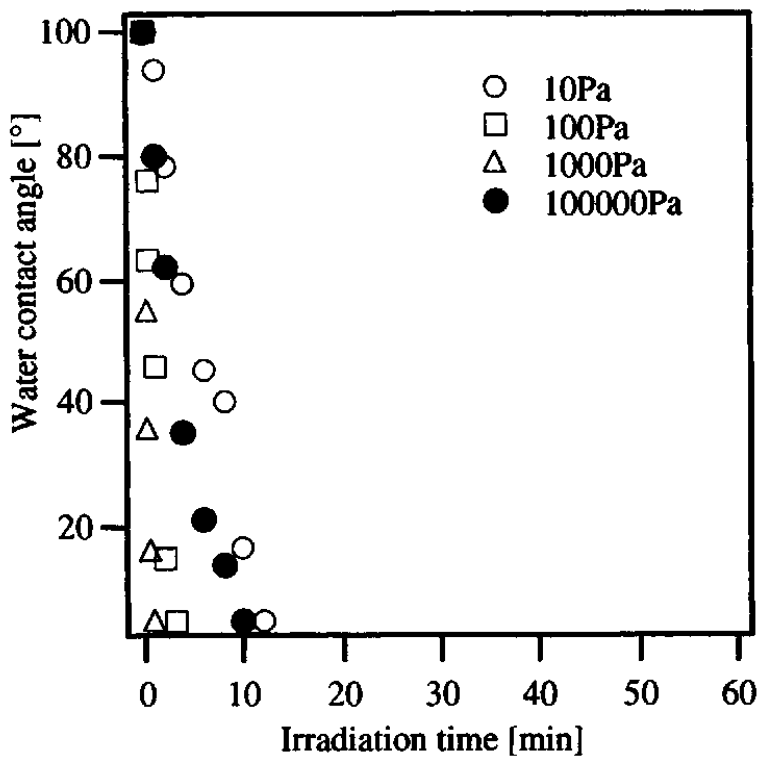

Fig. 5 Changes in water contact angle due to VUV-irradiation at $\mathrm{g}=10 \mathrm{~mm}$ and $\mathrm{d}=27 \mathrm{~mm}$.

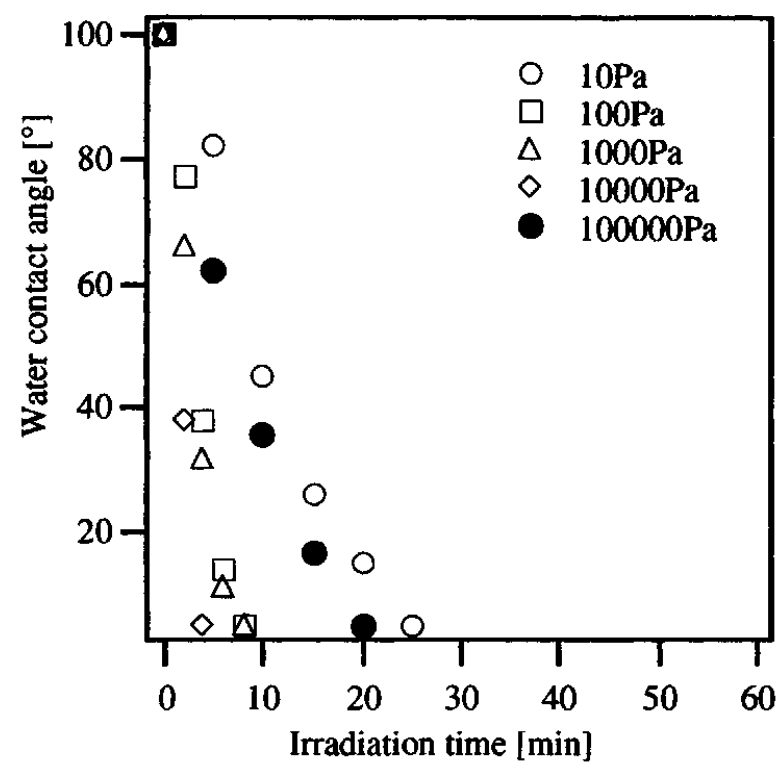

Fig. 6 Changes in water contact angle due to VUV-irradiation at $\mathrm{g}=0.0001$ $\mathrm{mm}$ and $\mathrm{d}=17 \mathrm{~mm}$. 
dation of the ODS-SAM. In addition, similarly to the configuration of $g=0$, the photodegradation rate increases when a pressure increases from 10 to $10^{4} \mathrm{~Pa}$ and decreases when a pressure further increases from $10^{4}$ to $10^{5} \mathrm{~Pa}$. The VUV-degradation attain a maximum rate in the pressure range between $10^{2}$ and $10^{4} \mathrm{~Pa}$.

Here we discuss the mechanism of VUVphotodegradation of the ODS-SAM. VUV-light dissociatively excites chemical bonds, e.g., C-C, C$\mathrm{H}$ and $\mathrm{C}-\mathrm{Si}$, and forms radicals [10]. Such radicals may further react with oxygen and water molecules in the atmosphere. However, the X-ray photoelectron intensity from oxidized products [11], e.g., - $\mathrm{COOH}$ and -CHO was in the undetectable range. Such products were also undetectable in IR-RAS. These results are different from that described in a recent report in which a C-Cl terminated SAM was converted to be covered with - $\mathrm{CHO}$ and $-\mathrm{COOH}$ head groups through a irradiation at $193 \mathrm{~nm} \mathrm{[7].} \mathrm{The}$ photodegradation chemistry for irradiation at 172 $\mathrm{nm}$ is thus not a simple conversion from hydrophobic alkyl headgroups to hydrophilic headgroups.

When organic molecules are irradiated with VUV-light in the presence of atmospheric oxygen, the VUV-light are simultaneously absorbed by organic molecules and oxygen. Atomic oxygen radicals are generated due to the VUV-excitation through two chemical reaction passes as described below.

$$
\begin{aligned}
& \mathrm{O}_{2} \stackrel{\mathrm{hv}}{\longrightarrow} \mathrm{O}(1 \mathrm{D}) \\
& \mathrm{O}_{2} \stackrel{\mathrm{hv}}{\longrightarrow} \mathrm{O}_{3} \stackrel{\mathrm{hv}}{\longrightarrow} \mathrm{O}_{2}+\mathrm{O}(1 \mathrm{D})
\end{aligned}
$$

Since these activated oxygen atoms have strong oxidative reactivity to organic molecules, the decomposed ODS-SAM due to the direct VUVexcitation further reacts with the activated oxygen atoms and is converted to volatile species such as $\mathrm{H}_{2} \mathrm{O}, \mathrm{CO}$ and $\mathrm{CO}_{2}$. The ODS-SAM is finally removed from the substrate. Most likely, hydrogen atoms were removed faster than carbon atoms as evidenced by Fig. 3. As can be understood from Fig. 1, a monolayer of $\mathrm{SiO}_{2}$ remains on the substrate even when all organic parts are removed from the ODS-SAM. The thickness of this remained $\mathrm{SiO}_{2}$ monolayer was estimated to be ca. $0.2 \mathrm{~nm}$ by ellipsometry.

A novel photolithographic process based on the VUV-photochemistry of ODS-SAM is demonstrated here. Figure 7A shows an LFM image of the
ODS-SAM irradiated through a photomask for 10 min at $10^{3} \mathrm{~Pa}$. The bright and dark regions in the images correspond to the photoirradiated and the masked areas, respectively. Microstructures composed of $2 \mu \mathrm{m} \times 10 \mu \mathrm{m}$ rectangular features were photoprinted on the SAM surface and was clearly imaged through the difference in friction between the photoirradiated and the unirradiated areas, that is, the undegraded ODS-SAM and the remained $\mathrm{SiO}_{2}$ monolayer surfaces, respectively. Due to chemical interaction with the AFM-probe surface, which is also hydrophilic because of its surface oxide, the hydrophilic $\mathrm{SiO}_{2}$ surface exhibits stronger lateral force than the hydrophobic, undegraded ODS-SAM surface. In such a case, hydrogen bondings may form between the sample and probe surfaces.

This photopatterned ODS-SAM was further used as an etching mask. Figure 7B shows an AFM image of the etched Si structure. the $\mathrm{Si}$ substrate was selectively etched in the photoirradiated areas while the unirradiated area was protected from the etching by the undegraded ODS-SAM.
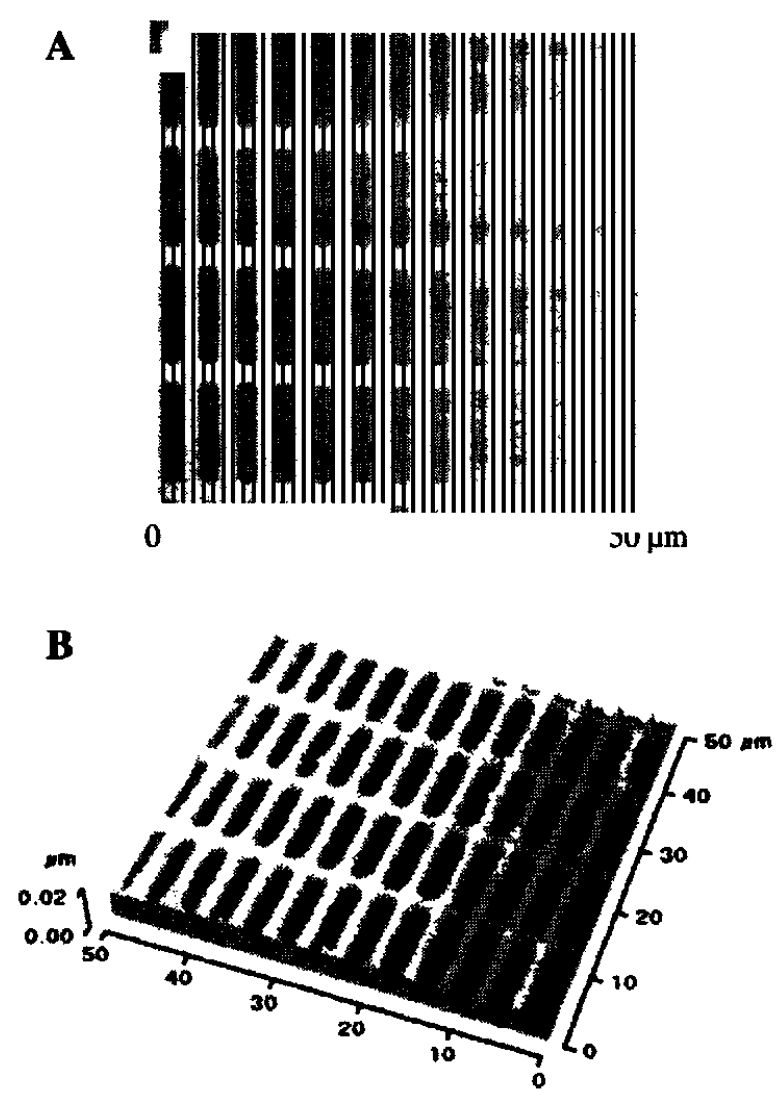

Fig. 7 Mirostructure fabricated by VUVlithography using ODS-SAM resist. (A) LFM image printed on ODS-SAM. (B) AFM image of etched $\mathrm{Si}$. 


\section{Conclusion}

The photodegradation of the ODS-SAM irradiated with VUV-light at $172 \mathrm{~nm}$ generated by an excimer lamp has been studied under various atmospheric pressures. The photodegradation rate increased with an increase in pressure from 10 to $10^{4} \mathrm{~Pa}$ while the rate decreased at a pressure of $10^{5}$ $\mathrm{Pa}$ because the light intensity attenuated due to increased light absorption by the atmospheric oxygen. The VUV-photodegradation mechanism of the ODS-SAM is concluded to be dissociative excitation of the organic parts of the SAM and subsequent oxidation reaction with atomic oxygen radicals generated by VUV-irradiation of $\mathrm{O}_{2}$ molecules.

On the basis of this VUV-photochemistry of organosilane SAM, a novel photolithography using SAM resist was demonstrated. Since this lithography is based on the photoclevage of C-C and $\mathrm{C}-\mathrm{H}$ bondings and, therefore, all of the organic molecules are regarded as photosensitive in the lithography, the VUV-photolithography using excimer lamps is applicable to micropatterning of any organic thin films.

This research has been supported by "Biomimetic Materials Processing" Research Project (JSPS-RFTF No. 99R13101), Research for the Future (RFTF) Program, Japan Society for the Promotion of Science.

\section{Reference}

1. E. P. Plueddemann, Silane Coupling Reagents, Plenum Press, New York, (1991); J. Sagiv, J. Am. Chem. Soc. 102 (1980) 92; S. R. Wasserman, Y.-T. Tao and G. M. Whitesides, Langmuir, 5 (1989) 1074.

2. W. J. Dressick and J. M. Calvert, Jpn. J. Appl. Phys. 32 (1993) 5829; M. J. Lercel, R. C. Tiberio, P. F. Chapman, H. G. Craighead,C. W. Sheen, A. N. Parikh and D. L. Allara, J. Vac. Sci. Technol. B, 11 (1993) 2823; P. C. Rieke, B. J. Tarasevich, L. L. Wood, M. H. Engelhard, D. R. Baer, G. E. Fryxell, C. M. John, D. A. Laken, M. C Jaehnig, Langmuir, 10 (1994) 619; R. Youkin, K. K. Berggren, K. S. Johnson, M. Prentiss, D. C. Ralph, G. M. Whitesides, Appl. Phys. Lett., 71 (1997) 1261; C. R. K. Marrian, F. K. Perkins, S. L. Brandow, T. S. Koloski, E. A. Dobisz and J. M. Calvert, Appl. Phys. Lett., 64 (1994) 390; H. Sugimura and N. Nakagiri, Langmuir, 11 (1995)
3623; H. Sugimura, K. Okiguchi, N. Nakagiri and M. Miyashita, J. Vac. Sci. Technol. B, 14 (1996) 4140.

3. S. P. A. Fodor, J. L. Read, M. C. Pirrung, L. Stryer, A. T. Lu and D. Solas, Science, 251 (1991) 767; S. Britland, E. Perez-Arnaud, P. Clark, B. McGinn, P. Connolly and G. Moores, Biotechnol. Prog., 8 (1992) 155; A. Takahara, K. Koiji, S.-R. Ge, T. Kajiyama, J. Vac. Sci. Technol. A, 14 (1996) 1747; D. C. Turner, C. Chang, K. Fang, S. L. Brandow and D. B. Murphy, Biophys. J., 69 (1995) 2782; H. Sugimura and N. Nakagiri, J. Am. Chem. Soc., 119 (1997) 9226; D. Kleinfeld, K. H. Kahler and P. E. Hockberger, J. Neurosci., 8 (1988) 4098. 4. J. M. Calvert, M.-S. Chen, C. S. Dulcey, J. H. Georger, M. C. Peckearar, J. M. Schnur and P. E. Schoen, J. Vac. Sci. Technol. B, 9 (1991) 3447; N. L. Jeon, R. G. Nuzzo, Y. Xia, M. Mrksich and G. M. Whitesides, Langmuir, 8 (1995) 3024; H. Sugimura and N. Nakagiri, Thin Solid Films, 281 (1996) 572; R. J. Collins, H. Shin, M. R. DeGuire, A. H. Heuer, C. N. Sukenik, Appl. Phys. Lett., 69 (1996) 860; K. Koumoto, S. Seo, T. Sugiyama, W. S. Seo and W. J. Dressick, Chem. Mater., 11 (1999) 2305; Z. Huang, ; P.-C. Wang, A. G. MacDiarmid, X. Xia and G. M. Whiteisides, Langmuir, 13 (1997) 6480.; T. Sato, D. G. Hasko and H. J. Ahmed, J. Vac. Sci. Technol. B, 15 (1997) 45.

5. C. S. Dulcey, J. H. Georger Jr., V. Krauthamer, D. A. Stenger, T. L. Fare and J. M. Calvert, Science, 252 (1991) 551.

6. N. Ichinose, H. Sugimura, T. Uchida, N. Shimo and H. Masuhara, Chem. Lett. (1993) 1961.

7. S. L. Brandow, M.-S. Chen, R. Aggarwal, C. S. Dulcey, J. M. Calvert and W. J. Dressick, Langmuir 15 (1999) 5429.

8. H. Sugimura and N. Nakagiri, Jpn. J. Appl. Phys. 36 (1997) L968; H. Sugimura and N. Nakagiri, Appl. Phys. A 66 (1998) S427; H. Sugimura, K. Ushiyama, A. Hozumi and O. Takai, Langmuir 16, (2000) 885.

9. H. Sugimura and N. Nakagiri, J. Photopolym. Sci. Technol., 10 (1997) 661; A. Hozumi, K. Ushiyama, H. Sugimura and O. Takai, Langmuir, 15 (1999) 7600.

10. A. Holländer, J. E. Klemberg-Sapieha, M. R. Wertheimer, Macromolecule, 27 (1994) 2893.

11. G. Beamson and D. Briggs, High Resolution XPS of Organic Polymers, Johon Wiley \& Sons, Chichester, (1992) 